\title{
Overcoming Barriers to Implementing Sustainable Development Goals: Human Ecology Matters
}

\author{
Roderick J. Lawrence ${ }^{1}$
}

Geneva School of Social Sciences (G3S), University of Geneva, Switzerland

\section{Abstract}

This article criticizes the framework provided by the United Nations 2030 Agenda for Sustainable Development, commonly used to implement sustainable development goals (SDGs). We argue that instrumental rationalism has been used to define cause-effect relations between "means" (all kinds of resources) and "ends" (the goals and targets) involved in implementing sustainable development. This linear thinking, commonly used during the last century, is applied again in the current agenda. Hence, too little attention has been attributed to human intentions, motives, preferences, and fundamental values that frame the constitution of societal institutions and structures, as well as individual and collective behaviors. These core constituents of human ecology are barriers to a new eco-social contact that endorses radical societal change for implementing sustainable development. Our research shows that innovative contributions are being achieved by local authorities and community-based initiatives in contrast to the denial and inertia of many national governments, public administrations, and private enterprises.

Keywords: anthropo-logic, eco-social contract, fundamental values, instrumental rationalism, means-ends model

In other words, sustainability requires a social avalanche of unprecedented proportions; to start this avalanche, enough momentum needs to be created for a snowball effect to develop, so that appropriate measures will be widely adopted. The question is: who or what might start this avalanche? (Fischer et al., 2012, pp. 158-159)

\section{Introduction}

Many national governments and public administrations have not been motivated to forgo short-term political interests and use sustainable development goals and targets to define and implement policies and programs. This inertia contradicts international acceptance of an agenda and framework for sustainable development

1 Corresponding author: roderick.lawrence@unige.ch. 
at the United Nations Conference on Sustainable Development (Rio+20) in June 2012 (United Nations, 2017). The main purpose of this article is to critically reconsider why the framework provided by the 17 Sustainable Development Goals (SDG 17), 169 targets, and their indicators has not been more effective in enabling societal change for overcoming the implementation deficit since 2015. Our research about the different types of barriers to implementing sustainable development highlights a strong focus on the core principles of sustainable development in many documents, even though the notion itself is still contested, three decades after it was endorsed by member states of the United Nations (Dovers \& Handmer, 1993). We posit that the core principles (e.g., the 5P Model) are founded on generalizations that have been used repeatedly to define development agendas during the last century. We argue that this framework does not provide a new eco-social contract for implementation; whereas it would have if the 5P Model had explicitly included human beliefs, intentions, motivations, preferences, and fundamental values. These core constituents of human culture define and are mutually defined by individualsociety-environment-biosphere interrelations (Lawrence, 2001). We argue that deciphering and acting with these constituents enables us to explain the persistence of conceptual, administrative, political, and sociobehavioral barriers, which are the root causes of ineffective individual and collective actions for implementing sustainable development. Until these core constituents, especially fundamental values, are counteracted and replaced by others, the "social avalanche" requested by Fischer et al. (2012, p. 158) will not happen.

We consider that core principles of sustainability (known as the "three pillars of sustainability," and the more recent 5P Model), used to formulate the 17 SDGs and 169 targets, have clearly presented the need to understand and respond to global challenges (such as loss of biodiversity, climate change, persistent poverty, etc.). However, responses to these global challenges are framed as "the ends" or outcomes that should be achieved and sustained by countries even though there may be a lack of agreement about them. Some goals and targets present "the means" (e.g., SDG 17 includes education, funding, training, and partnerships) required to achieve the goals and targets. There is an implicit assumption, based on linear causality, that if enough means are allocated then the desired ends will be achieved. This assumption ignores the societal context and preconditions that underline using "the means" to achieve "the ends;" it ignores human intentionality, interests, motives, preferences, and fundamental values that individuals and institutions use, explicitly and implicitly, to position themselves regarding personal and social change for sustainable development. We argue that these behavioral, institutional, and political dimensions should be addressed explicitly because they are the cultural foundations on which societal barriers persist and are sustained in a value-laden world (Fischer et al., 2012; Lawrence, 2005). Finally, we argue that these cultural 
and societal conditions should be understood from a human ecology perspective before more effective implementation of the United Nations 2030 Agenda for Sustainable Development can be achieved.

\section{Method}

The research method for this article is the documentary analysis of published databases, statistics, and reports that record contributions about implementing sustainable development goals and targets since the 1990s. These official documents indicate ineffective societal responses to global challenges (including climate change, loss of biodiversity, poverty, and malnutrition) at international and national levels, despite concordant empirical data and increasing scientific knowledge about them (Lawrence \& Gatzweiler, 2017). In contrast, the author's collaboration with some international programs since the 1990s has documented numerous achievements at the level of local authorities. Moreover, the author's review of the Global Sustainable Development Report 2019, on behalf of the Swiss Academy of Sciences, indicates that international diplomacy and national political agendas can provide contextual conditions for effective responses to societal challenges at the geopolitical level of cities and local authorities (United Nations, 2019). Our research confirms that innovative projects and programs about active living, food, housing, and transport can serve as beacons for societal change towards more sustainable cities and communities, and some of these exemplary cases will be mentioned.

\section{Understanding anthropo-logic}

The term anthropo-logic designates an integrated knowledge domain of human groups and societies, including their aesthetic, conceptual, ethical, and technical knowledge, as well as their technical and practical know-how, and how these are expressed by cultural traits. The term is derived from anthropos, which designates what is specifically human; "logic" is derived from the ancient Greek word logos and designates thought, reasoning, and discourse. The proposed anthropo-logic is derived from a holistic and systemic conceptual framework of human ecology that includes the content and symbiotic interrelations between an eco-logic and a bio-logic in addition to an anthropo-logic (see Figure 1). Anthropo-logic is the primary focus here because, in general, sustainability research and policy has not attributed sufficient attention to core cultural dimensions of the themes or situations studied, including climate change, loss of biodiversity, malnutrition and poverty, and increasing socioeconomic inequalities. 


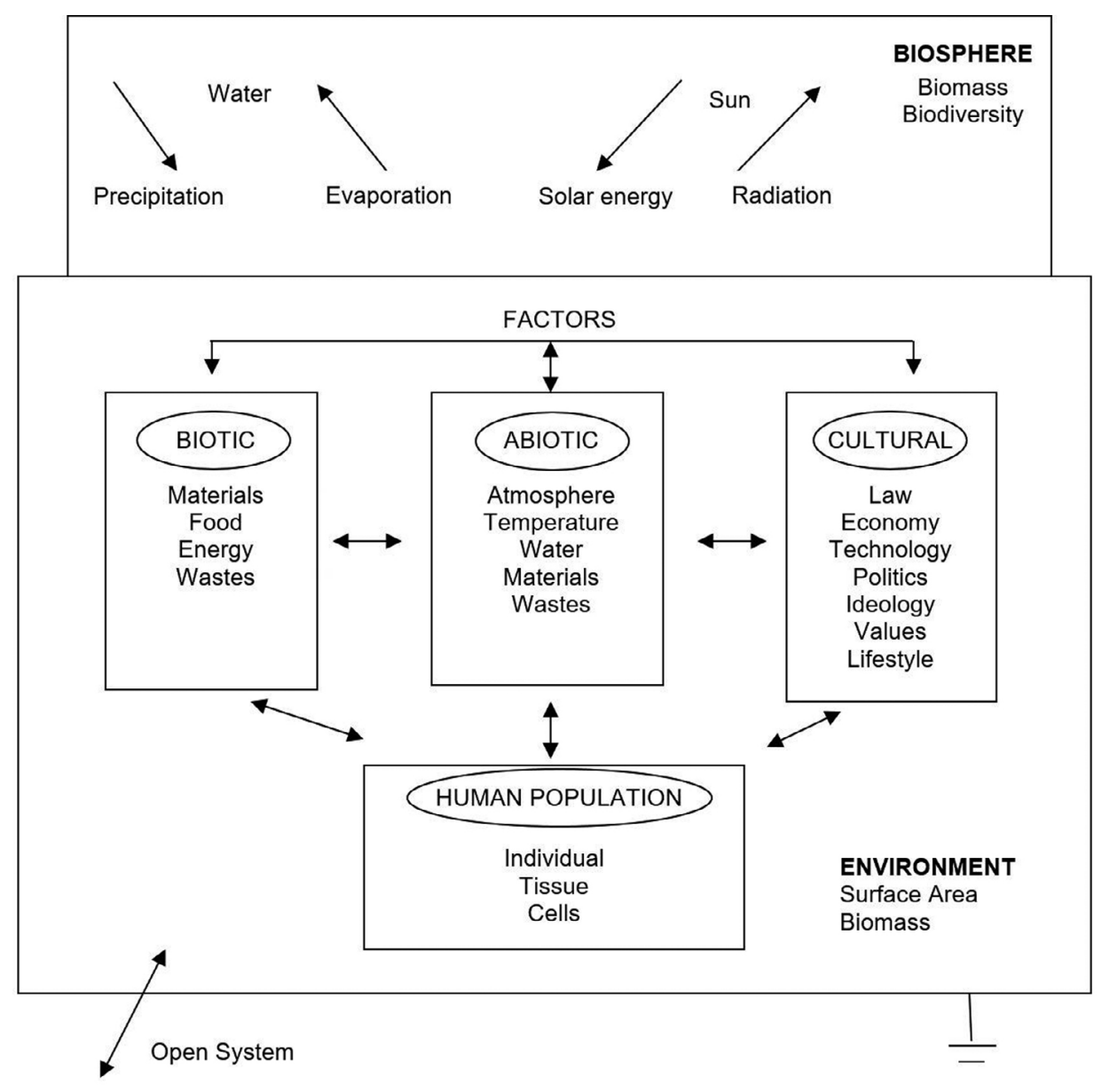

Figure 1. The holistic and systemic framework of a human ecology perspective, showing the interrelations between biotic factors, abiotic factors; cultural, social, and individual human factors; and artifacts which are delimited by situations, habitats, or larger ecosystems.

Source: Provided by the author.

Human ecology provides a holistic framework and systemic interpretation of different knowledge domains, including the arts, humanities, social sciences, and natural sciences. It illustrates the reciprocal relations between sets of biotic, abiotic, and anthropogenic factors. Hence, it considers the whole system as the unit of study in precise localities. The broad conceptual and methodological framework proposed here is grounded in understanding societal contexts, in stark opposition to reductionism. Contextualism underlines that meanings of knowledge and applications of know-how are grounded in specific situations. This conceptual model can be applied at different geographical scales to deal with specific themes or situations about sustainability (Lawrence, 2005). It offers a synchronic representation of a human ecosystem that is open and linked to others. The model is meant to be 
reapplied at different times to explicitly address a short- and long- term historical perspective. This dual temporal perspective can identify change to any of the specific components as well as the interrelations between them.

The next section summarizes the international background, the institutional framework, and the rational thinking used to formulate the United Nations 2030 Agenda for Sustainable Development endorsed in 2015 (United Nations, 2015). Then, we critically analyze the pragmatic thinking used to formulate the 17 SDGs, the 169 targets, and their indicators, which we consider as applied instrumental rationalism (see later). Despite its good intentions, this agenda for implementing transitions to sustainable development has not been wholly successful, especially at the national geopolitical level (Lopez-Claros et al., 2020; United Nations, 2017). Surprisingly, our research found that there are few contributions about different types of barriers to more effective implementation. In that global context, we explain how local authorities and community-based associations have bypassed the denial or inertia of many national authorities to implement creative and innovative programs and projects that are exemplary examples of transitions to sustainability. These contributions confirm the necessity of removing conceptual, administrative, and sociopolitical barriers that inhibit a new anthropo-logic and an eco-social contract which enable more effective implementation. This way forward endorses the importance of fundamental values and the core principle of subsidiarity included in Agenda 21 in 1992 (United Nations, 1992); both should be more widely acknowledged, because cities, local authorities, and community-based initiatives have become beacons for change for sustainable development, especially in response to many global challenges including: climate change and extreme weather events; provision-efficient energy infrastructure; supplies of renewable energy sources; malnutrition and access to affordable fresh food; and public health campaigns concerning infectious and noncommunicable diseases (Lawrence, 2021).

\section{Transitions to sustainability: Taking stock}

In 2015, the United Nations General Assembly endorsed 17 Sustainable Development Goals that enlarged and replaced the 8 Millennium Development Goals and 18 targets that were implemented and monitored between 2000 and 2015 (Kenny, 2015). Each goal represents a global challenge that should be understood and addressed in order to transit towards sustainable development. The SDGs have been developed and endorsed by member states of the United Nations on the understanding that they will be accepted and implemented nationally, with international financial and technical support where deemed necessary (United Nations, 2015). This approach is envisaged in Transforming Our World as a generic blueprint that can be adjusted in precise situations to achieve sustainable development using core principles of "universality," "leaving no one behind," "interconnectedness and indivisibility," "inclusiveness," and "multi-stakeholder partnerships" (United Nations, 2015). 
The United Nations identified the 17 SDGs, their 169 targets, and their quantifiable indicators as outcomes ("the ends") that are achievable, quantifiable, and can be monitored from 2016 to 2030 (e.g., SDGs 6 and 7), and "the means" of achieving a broad range of urgent and universal issues for the period (e.g., SDG 17) through multi-stakeholder partnerships that recognize the benefits of cooperation between the private sector, public administrations, and civil society (Monkelbaan, 2019). Since the publication of Agenda 21 (United Nations, 1992), the United Nations has emphasized the importance of allocating enough means for the implementation of sustainable development. The range of means proposed are not limited to financial resources and funding, because capacity-building, education and training, scientific research, and partnerships have been discussed during the last two decades.

In operational terms, the United Nations 2030 Agenda for Sustainable Development does not provide new insights about impediments, despite contention about the amount of financial resources allocated to implement the SDGs, especially given that many countries have not respected their commitments. Notably, there is no clear statement of how "means" and "ends" should be interpreted. According to Elder et al. (2016), some goals and targets have several functions because they can be considered as 'intermediate means' to achieve predefined targets. Consequently, these authors underline that "goals as means" should be a key concept that was not used when the SDGs and their targets were formulated and agreed.

There is broad agreement that the 17 SDGs and 169 targets provide a framework for country-effective responses to major global challenges, if appropriate means and measures are available. This is an example of thinking based on linear causality that assumes a direct relationship between "means" and "ends," without considering plausible intervening variables, notably human motivations, that modify this causeeffect relationship. It ignores the societal context, especially the administrative, economic, financial, institutional, political, and social variables that can modify this binary relationship; contextual variables account for differences between countries, states, and cities. This way of thinking also underlies other shortcomings: for example, a paragraph in Transforming Our World states that "in accordance with the Charter of the United Nations, the need to respect the territorial integrity and political independence of States" is reaffirmed (United Nations, 2015, para. 38). Notably, the overall legal and institutional frameworks of non-binding, voluntary commitment and "soft law" that is not legally binding, are not challenged even though they are well-known barriers that do not guarantee compliance with international agreements or implementation. Lopez-Claros et al. (2020) describe in much detail why this institutional, legal, and political system has not been effective in facilitating and enacting societal change for sustainable development by countries since the 1970s. Despite these persistent shortcomings, it is assumed that current institutional, fiscal, and legal frameworks and mechanisms for implementation can be reformed, whereas we agree with Lopez-Claros et al. (2020) that they should be replaced. 
Christian Berg (2020) stated that barriers to achieving societal change for sustainable development have rarely been studied systematically. He proposed an actor/institutional framework to help overcome the inertia between the goals and targets ("the ends") formulated and endorsed in numerous official documents, and the lack of resources ("the means") restricting or prohibiting programs and projects that are meant to achieve them. We note that the German Advisory Council on Global Change (WBGU²) discussed barriers for societal change for sustainable development in terms of "path dependencies," "tight time frame," "obstruction of global cooperation," "rapid urbanization," and "easily available supply of coal" (WBGU, 2011). This small heterogenous set of topics proposed a decade ago should have been complemented by numerous others, including ineffective institutional, legal, and political arrangements; growing neoliberal market economies with the subservience of politicians and public administrations to multinational corporations; and individual and collective lifestyles that champion consumerism and self-interests for the sake of "the good life."

Notably, the Global Sustainable Development Report 2019 acknowledges the need for intentional change but continues to propose current institutional, fiscal, and legal arrangements and mechanisms for implementation (United Nations, 2019). That report, written by an independent group of scientists, has followed the thinking of academic authors of many other documents which have presented the major pressures that threaten natural and human-made ecosystems, health, and well-being without analyzing the root causes of these pressures (more on this later).

Here we apply a different reasoning, by extending the contribution by Joern Fischer et al. on behalf of the Earth Stewardship Initiative (Fischer et al., 2012). Their contribution indicated why contributions of scientific research had not served as a catalyst for societal change towards sustainability. They concluded that the primary barrier to societal change was not lack of data, information, and knowledge about persistent problems; instead, inertia is grounded in human behavior, intentionality, preferences, values, and worldviews. Hence, societal change is dependent on "reflecting on deeply held value and belief systems, which fundamentally shape behaviour" (Fischer et al., 2012, p. 153). We live in a value-laden world; therefore, it is the personal and shared experiences, perceptions, and values associated with persistent problems and global challenges that count, not just the addition of the number of people concerned. Until current fundamental values are identified, counteracted, and replaced, there will be no "social avalanche" (Fischer et al., 2012, p. 158).

2 Wissenschaftlicher Beirat der Bundesregierung Globale Umweltveränderungen (WBGU) [German Advisory Council on Global Change]. 
Values convey the relative importance of objects, events, situations, challenges, and problems. They are guiding principles that influence human aspirations, choices, intentions, and goals, and which are embedded in human interpretations of these challenges and problems, and responses to them (Lawrence, 2005). Individual, group, societal, and fundamental cultural values coexist in precise localities and with respect to specific themes. Notably, Dyball and Newell (2015) confirm that human ecologists have accounted for values, but they have often used the term narrowly, referring to a numerical amount, magnitude, or monetary value of objects, or a quantity of material things (e.g., the stocks of ecosystems). We enlarge common interpretations of value to include aesthetic, cultural, moral, and spiritual values, because these are embedded in the core principles of sustainable development that endorses human rights, as well as environmental and social justice.

Values are incorporated in the anthropo-logic of the human ecology framework we proposed in Figure 1. Given that sustainable development is anthropocentric, and a normative concept, it is difficult to understand why much more attention has not been paid to improving understanding of the diversity of human beliefs, goals, priorities, and values that coexist in a heterogenous world. Notably, different and especially conflicting experiences, intentions, perceptions, and values should be understood and dealt with more effectively than they are by conventional processes for consensus-building, which do not confront incommensurability.

The following section of this paper summarizes the 5P Model endorsed by the United Nations and discusses this framework for formulating the 17 SDGs and 169 targets in terms of outcomes and means. We posit that the rationale for this approach included encouraging the implementation of the United Nations 2030 Agenda for Sustainable Development. This approach applies the logic of instrumental rationalism (described later), as a way of thinking that dominated development agendas, and many interpretations of economic growth and development, during the last century (Daly, 1973). We argue that this kind of pragmatic thinking has rarely dealt with the human beliefs, intentions, meanings, perceptions, and values that are embedded in the conceptual, administrative, political, and sociobehavioral barriers that have inhibited societal transitions for sustainable development during the last 30 years, not just since 2015. We then present an alternative forward look which explicitly addresses an anthropo-logic that should be incorporated in a new eco-social contract that is not prescribed or imposed by international or national authorities but supported by local and national authorities and produced communally (Fischer et al., 2012). Our research since 2015 confirms that local authorities and community-based initiatives are implementing innovative programs and projects in many cities (Lawrence, 2021). 


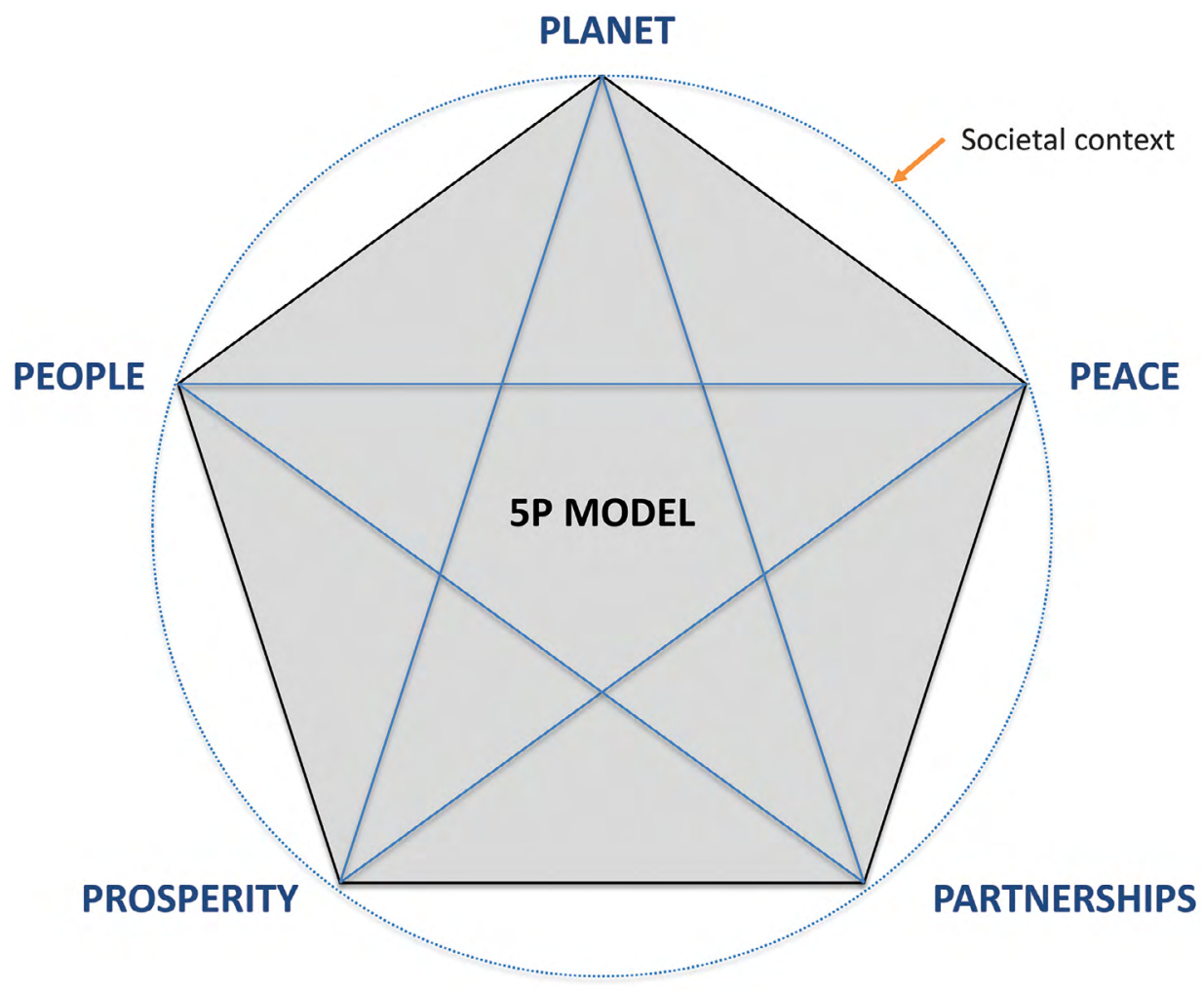

Figure 2. Author's representation of the 5P Model of sustainable development endorsed at the United Nations Conference (RIO+20) held in June 2012.

Source: United Nations (2015).

\section{The United Nations 5P Model}

The United Nations 2030 Agenda for Sustainable Development provides a broad and global framework that has been named the 5P Model, shown in Figure 2, which denotes: people, planet, prosperity, peace, and partnerships (United Nations, 2015). This framework was meant to reiterate principles and recommit the 193 member states of the United Nations to implementing sustainable development using a broader framework for action than the well-known three pillars of environmental, economic, and social parameters proposed in the Brundtland Report (World Commission on Environment and Development, 1987), and endorsed at the United Nations Conference on Sustainable Development in 1992.

The 5P Model for sustainable development presented in Transforming Our World: The 2030 Agenda for Sustainable Development is founded on the following meanings and their applications (United Nations, 2015). First, people denotes a humane approach, founded on the core principles of environmental and social justice, that should reduce poverty and hunger while promoting secure and safe living 
conditions that encourage health and well-being. This interpretation endorses the primary definition of sustainable development given in the Brundtland Report (World Commission on Environment and Development, 1987); the first principle of the Rio Declaration on sustainable development (United Nations, 1992); and the first Millennium Development Goal applied between 2000 and 2015. However, this people component does not explicitly address the influence of human beliefs, motivations, values, and worldviews that are the foundations of an anthropo-logic that frames individual-society-environment-biosphere interrelations (Lawrence, 2005). These interrelations define and are defined by the way that individuals and groups think they should live, sustain their livelihoods, and relate to others in a world of uncertain futures and unpredictable change.

Second, planet refers to evolving global environmental conditions, including climate change and loss of biodiversity, and how these trends are influenced by human activities, including consumption and production processes, uses of natural resources, and whether human needs of current and future generations will be met. During the last 30 years this has been known as the environmental pillar of sustainable development and it was founded to encourage environmental protection and nature conservation. Arthur Dahl (1996) explained that sustainable development denotes a process (rather than an outcome) that is voluntary, not mandatory, and that environmental concerns are constructs of human thinking and behavior.

Third, prosperity refers to the livelihoods for all human beings provided by economic, social, and technological progress. This equates development with economic growth, technological development, and income; it was the foundation of the original economic pillar of sustainable development in Our Common Future (World Commission on Environment and Development, 1987). Notably, that landmark document emphasized moral values that express fundamental ethical principles about environmental and social justice that have been included in the current agenda.

Fourth, peace denotes fostering just and inclusive societies without violence, warfare, or a sense of insecurity. However, fundamental human values and ethical principles about increasing ethnic, gender, and socioeconomic differences should have been underlined, whereas this component endorses the social pillar of the original sustainable development triad.

Fifth, partnership refers to "the means" required to implement the United Nations Agenda for Sustainable Development by public-private partnerships, based on a spirit of strengthened global solidarity, with the participation of all countries, stakeholders, and laypeople. Partnerships were endorsed at the World Summit on Sustainable Development held in Johannesburg in 2002 (United Nations, 2002). They require a fundamental shift in values that has not been highlighted. 
In addition, the pertinence of human-centered contributions by major groups, founded on the principle of subsidiarity endorsed in Agenda 21 in 1992, should have been underscored in the current agenda.

Morton et al. (2017) suggested that the 5P Model accepted by member states of the United Nations in 2015 is related to the 17 SDGs in the following way. They associate SDGs 1, 2, 3, 4, 5 and 6 to people; then SDGs 13, 14 and 15 are classified with planet, whereas SDGs 7, 8, 9, 10, 11 and 12 are associated with prosperity. Peace is related to SDG 16 and partnership with SDG 17. This unilateral classification ignores plausible multiple interconnections between the 17 SDGs that should be identified by relational and systems thinking because the SDGs are not independent of each other and some can be located in more than one of the 5P categories: for example, decent work is a constituent of SDG 8 that should also be allocated within people, not just prosperity, because it has an influence on health and well-being, gender equality and poverty (Lawrence $\&$ Werna, 2009). The issue of categorization has been discussed by Mark Elder et al. (2016).

A functional classification of the 17 SDGs has been proposed by Elder et al. (2016) according to six categories: social objectives (SDGs 1, 3, 4, 5, 10); resources (SDGs 2, 6, 7 ); economy (SDGs 8, 9, 11, 12); environment (SDGs 13, 14, 15); education (SDG 4); governance (SDG 16); and SDG 17 is a means of implementation. Then the authors analyze scientific and political debate about implementing all SDGs as an extension of the plan for implementation of sustainable development, defined in conjunction with the World Summit on Sustainable Development held in Johannesburg in 2002 (United Nations, 2002). The authors emphasize that one or more goals can be a means to achieving other goals. They question common distinctions between "the means" proposed to achieve all goals ("the ends"), and the functions of each goal, because some goals can serve as enablers to achieve other goals; for example, sustained supplies of energy (SDG 7) and water (SDG 8) are necessary for food production that reduces hunger (SDG 2) and alleviates poverty (SDG 1) while enabling health (SDG 3). This broad interpretation of means extends well beyond that proposed for SDG 17 in the United Nations documentation, and highlights the importance of understanding interrelations between all 17 goals and their targets.

There is a regrettable lack of relational thinking in the definition of the SDGs and their connectivity. For example, SDG 17 proposes partnerships as an important means for implementing sustainable development, whereas partnerships are not mentioned in the other 16 SDGs. Some operational frameworks have attempted to define connections between different goals and targets in terms of the type and strength of interrelations between them. For example, a report by the International Council for Science (2017) presents a conceptual tool for evaluating target-level interactions between various SDGs in precise situations. Scores are assigned to specific interactions based only on expert judgment and scientific evidence. Notably, scores 
implicitly express values, but the core issue of whose values is not addressed. Instead, the approach is based on the premise that understanding both the positive synergies and the trade-offs among SDGs is critical to prioritizing action. Such understanding can help to predict whether progress towards a goal will facilitate or hinder progress in another. Hence the International Council for Science report presents an expert approach to evaluating and scoring plausible interactions between SDGs (Nilsson et al., 2016). The approach is applicable in different situations and at different geopolitical levels. However, because it is grounded only in scientific expertise that does not account for fundamental cultural, social, and personal values, it does not incorporate core constituents of societal conditions on which change for sustainable development depend. Consequently, the objective of implementing the SDGs and advancing towards their targets can be jeopardized at the outset because sustainable development cannot be achieved in a vacuum. We argue that this fundamental shortcoming can be attributed to instrumental rationalism, which we briefly explain in the following section.

\section{Sustaining what: Instrumental rationalism?}

Instrumental rationalism is pragmatic and denotes human actions that associate "the means" or inputs to achieve "the ends" (e.g., desired goals or outputs). It means that individuals and institutions use those means (e.g., the provisions deemed necessary) to achieve desired ends. Conversely, human action that is incoherent or contradictory to achieving desired goals or outcomes is deemed irrational. Research confirms that "the means" do not guarantee "the ends," but they do influence the interrelation between them. The term "end" can refer to a state or condition, or an action or process. Hence, the issue of whether appropriate and enough means have been attributed to achieve desired goals and targets is dynamic; a core challenge involves identifying and applying adequate means to achieve desired outcomes in a dynamic and changing world (Kolodny \& Brunero, 2018).

The United Nations 2030 Agenda for Sustainable Development has applied instrumental rationalism to deal with societal challenges that require effective responses for transitions to sustainable development. Indeed, instrumental rationalism is also pertinent for understanding contributions of specific governments, public institutions, and firms in the private sector to sustainable development programs and projects during the last 40 years. Notably, Herman Daly (1973, p. 8), a founder of ecological economics committed to sustainable development, proposed a meansend model, which included a hierarchy of intermediate and ultimate means for sustainable development. In this context, "ultimate means" denotes the underlying natural resource base and the life-support system of the planet; whereas "ends" and "ultimate ends" denote human well-being measured by a composite index not limited to gross domestic product. 
Twenty-five years after this contribution, Donella Meadows (1998) adapted this hierarchical means-end model into a circular one that represented systems thinking. She explained that "means" denotes "inputs" in systems thinking, whereas intermediate and ultimate "ends" denote "outputs" in systems thinking, and represent the goals for sustainable development. Mark Elder et al. (2016) explained that this model has been used implicitly or explicitly during the last two decades by organizations, researchers, and policy-makers who have formulated sets of indicators for sustainable development. Notably, since 1992, the means-ends model has been a recommended framework for developing indicators for sustainable development, according to Chapter 40 of Agenda 21 (Meadows, 1998).

Arthur Dahl (2018) described the history of the development of indicators of sustainable development coordinated by the United Nations Environment Programme. This history builds on contributions from international organizations, including the Environment Division of the Organisation for Economic Co-operation and Development (OECD) and the World Health Organization (Pintér et al., 2014). All the frameworks discussed in this history represent linear causal pathways between drivers or pressures on environmental, economic, or social conditions, and their consequences (state, exposures, and effects, which are "outcomes") for components of natural ecosystems, human health, and well-being. The drivers and the outcomes are tangible and measurable conditions or processes, whereas the human motives, objectives, and values underlying them are not identified and analyzed. The global indicator framework continued this approach for the United Nations 2030 Agenda for Sustainable Development; it was developed by the InterAgency and Expert Group on SDG Indicators and agreed to as a practical starting point at the 47th session of the UN Statistical Commission held in March 2016. This framework has not questioned the shortcomings of instrumental rationalism, or linear causality, that overlook fundamental human values. We argue that the drivers of unstainable human activities are the motives, objectives, and values that prioritize individualism above communalism, egoism above altruism, self-interest above the common good. They are core components of an anthropo-logic that has gathered strength during the last century (Dahl, 1996). The remaining sections of this article propose a fundamentally different way forward that includes fundamental values that need to be addressed if societal transitions towards sustainability are to overcome the implementation deficit.

\section{Rehumanizing sustainability: A forward look}

The United Nations' Global Sustainable Development Report (United Nations, 2019) mentioned earlier presents the contribution of a group of 15 academic researchers and scientists about achieving the desired societal change for sustainable development using extant legal and institutional arrangements, market mechanisms, 
and partnerships with public authorities and community associations. The report discusses the urgency and expectations about implementing change by proposing six entry points that are interrelated with the 17 SDGs and 169 targets. These entry points are:

- human well-being and capabilities;

- sustainable and just economies;

- food systems and nutrition patterns;

- energy decarbonization with universal access;

- urban and peri-urban development; and

- global environmental commons.

The report also identifies four levers, which can be coherently deployed through each entry point to bring about required change:

- governance;

- economy and finance;

- individual and collective action; and

- science and technology.

These four levers are related to the means of implementation discussed in SDG 17.

Each lever can contribute individually to systemic change. However, the report argues that it is only through their context-dependent combinations that it will be possible to bring about the transformations necessary for balancing across the dimensions of sustainable development in order to implement the United Nations 2030 Agenda for Sustainable Development. We endorse this approach, and emphasize that it should address fundamental human intentions, motives, preferences, and core values that have been drivers of the globalization of production and consumption processes, the increasing privatization of community services and infrastructure, and the retreat of the state interventions and lower expenditure on public health, education, and welfare services in many countries.

Notably, this report, like other official documents published before it, overlooks the consequences of globalization, and the shift to neoliberal market economies since the 1980s, coupled with the erosion of the role and responsibility of the state and public administrations. These ongoing processes around the globe have reduced the resilience of many countries and cities to counteract global threats, because they have lost their capacity to act autonomously after becoming subservient to global production processes and trade with foreign countries in international markets. In this international geopolitical context, the individual initiative of 
citizens, households, and communities cannot counteract the global trend towards centralization resulting from the power and influence of multinational corporations and their collusion with political authorities across all geopolitical levels.

Whereas numerous contributions discuss the need for more data and information, we agree with Fischer at al. (2012) that this is not always the case (Lawrence \& Gatzweiler, 2017). Likewise, there are alternative technologies, alternative institutional and legal frameworks, and alternative business models that can replace "business as usual." We argue that a new eco-social contract is required but it has not been provided by the United Nations 2030 Agenda for Sustainable Development. This eco-social contract should be founded on ethical principles and moral values, incorporating both fundamental monetary and non-monetary values, which are the root causes of egocentric human behavior and short-term institutional and political actions that should be challenged and replaced by collective eco-centric visions about a common future. Our research confirms that innovative community-based initiatives are now being scaled up to have a broader societal impact (Lawrence, 2021). These innovative projects, among numerous others, highlight the need to understand and remove different types of barriers to societal change.

Henceforth, international organizations, national institutions, and local authorities should not ignore the reasoning of individuals, households, community associations, private enterprises, and public administrations to adhere to, or reject, certain sustainable development goals or targets and the allocation of the resources necessary to achieve them. There is too little research that documents why initiatives that are meant to respond to the risks of climate change and extreme weather events, or to epidemics of contagious diseases as well as the growing incidence of noncommunicable diseases, or to increasing economic, housing, and health inequalities between countries and within large cities, are not being implemented where they are most needed. We have called this dilemma "the applicability gap" (Lawrence, 2015) and explained that the distinction between "what we know" and "what we do" does not depend only on availability of data and information, but primarily on beliefs, desires, intentions, motives, perceptions, and values that may be egocentric and self-centered, or altruistic and communal. These core constituents of human culture form an anthropo-logic which is the foundation of the conceptual, administrative, and sociopolitical barriers that hinder social change for sustainable development before and since 2015. These types of barriers will be described in the following section. While some authors, including Fischer et al. (2012) and Berg (2020), have confirmed their importance, we stress that dismantling them to their foundations is a precondition before more effective programs and projects will overcome the implementation deficit. 


\section{Overcoming the implementation deficit}

Beyond radical reforms required in international and national governance, and the redefinition of legal, fiscal, and institutional arrangements, we consider that the lack of attention given to human beliefs, intentions, motives, preferences, and values needs correcting because they are the foundations of conceptual frameworks and models, administrative and legal arrangements, and cultural values, behavioral norms, and social conventions that have commonly been used uncritically by authors and institutions to define and implement sustainable development. We explain our position in the following paragraphs.

First, conceptual barriers refers to the common use of inapt analogies, metaphors, and models that are meant to represent relations between anthropos and cosmos, and between natural ecosystems and human-made environments (Lawrence, 2001). Although sustainable development is anthropocentric, this does not mean that humans are separated from natural ecosystems, or the biosphere, on which they are dependent. We have argued that human ecology provides a holistic conceptual framework that combines abiotic, biotic, and cultural (or anthropo-) logics and the symbiotic relations between them (see Figure 1). This model is meant to replace a hierarchical one in which humans have dominion and can manipulate natural ecosystems. Human ecology applies a radically different set of fundamental values to that used in hierarchical models that rank humans at the pinnacle, or mechanical models that express rational, utilitarian approaches including instrumental rationality. We have noted that systemic thinking and models are still rarely applied for understanding the multiple relations between sustainable development goals and targets. Hence contradictions or trade-offs are ignored in specific situations, including key questions about the purpose of sustainable or other types of development.

Second, administrative and institutional barriers are the segmented and uncoordinated formulation and conduct of projects and programs that fail to adopt a compound and coordinated understanding of individual-society-environment-biosphere interrelations. Unfortunately, formal education and training have created roles and responsibilities for scientists, professionals, public administrators, and citizens from "all walks of life," delimited by discipline-based knowledge and professional knowhow. This specialization and segmentation of functions in both public and private sectors has created specialists that isolate their concern about a situation or problem from its real-world context, as Rittel and Webber noted (1973); they explained how core values are embedded in human interpretations of societal problems. In contrast, scientific problems are meant to be value-neutral; experts apply instrumental rationalism largely driven by quantitative data and statistical analysis, whereas qualitative meanings and preferences that express values and worldviews are rarely included. Consequently, many administrative and institutional contributions grounded only on the results of this kind of scientific research have failed because 
they have only addressed the measurable conditions of economic, environmental, and social conditions of problems rather than their root causes. If these causes are not understood, then effective corrective measures cannot be implemented.

Third, behavioral and social barriers refers to the attitudes and actions of all humanspoliticians, property owners, public servants, and laypeople-who have personal and shared beliefs, intentions, motives, and preferences about what constitutes quality of life, well-being, and the common good, and what behaviors are acceptable to achieve them. In heterogenous societies, there is rarely consensus about how these core constituents of culture and behavior are associated with individualsociety-environment-biosphere interrelations. Indeed, there frequently are conflicts between contrasting viewpoints; this also explains why sustainable development is still strongly contested by some and distorted by others for egocentric benefit.

We argue that until these three sets of barriers are understood, they cannot be removed. The contribution of Otto Scharmer is one approach that has been applied successfully in different situations to achieve this objective. Theory $U$ was formulated by Otto Scharmer $(2016,2018)$, who posits that there is an urgent need for a societal shift from the strong focus on individualism and egocentric thinking to ecosystems awareness and a shared consciousness. This collective mindset is needed before persistent global trends, including climate change, loss of biodiversity, and increasing socioeconomic inequalities can be counteracted by concerted action. Scharmer has consistently explained that human awareness and consciousness of leading decision-makers is a common obstacle to societal change. In order to change the mindset of leaders, Theory $U$ proposes the rethinking of fundamental existential issues of our identity in society and our status in the world. This critical thinking should consider core values about the position and status of humans and all other living beings on the planet. According to Scharmer (2018), any fundamental societal change will require a shift from an egocentric society to an ecosystemic one that cares about nurturing all beings on Earth.

Scharmer's approach enables participants from all sectors in society to converge and collaborate in order to change existing situations that are problematic. His collaborative contribution includes five phases: co-imitating and listening to others in order to establish a common ground for participants; co-sensing, observing, and reflecting with an open mind about the position of oneself and others; presencing by systemic thinking about where each participants would like to be and what changes are required to get there; cocreating prototypes that can serve as experiments to test change in real-world situations; and coevolving in order to review, confirm, and sustain the outcomes of the collaborative process that has formulated and tested plausible futures. The approach identifies "blind spots" (including hidden assumptions, misconceptions, and unknowns) in common debate about problematic situations and societal trends. Once these blind spots have been identified and understood by all participants, then it is possible for them 
to reposition themselves in relation to a problematic situation of mutual concern by considering alternative futures rather than reacting only to patterns or processes of the past.

\section{Conclusion}

This article highlights the limitations of conventional contributions that discuss implementing sustainable development using frameworks, including the United Nations 2030 Agenda for Sustainable Development since 2015. The article presents the content and rationale of a more comprehensive approach than the framework provided in the 5P Model for sustainable development and the 17 SDGs and 169 targets that are meant to encourage implementation of societal change for sustainable development. This societal shift should combine and coordinate individual, group, and societal change using the anthropo-logic of human ecology. This enlarged approach, illustrated by Theory $U$, includes initiatives that have bridged the knowledge-practice divide in numerous sectors at the level of cities and community initiatives (e.g., environment, energy, food, health, housing, land use, and transport). Many innovative programs and projects involving laypeople have been studied since 2015 (Lawrence, 2021). We conclude that community-based transdisciplinary project implementation has shifted beyond conventional project and policy-making agendas to address fundamental values and shared concerns about living conditions of current and future generations in a world undergoing rapid change. Hence the fundamental constituents of an anthropo-logic have been deciphered, understood, and then used creatively during concerted action at the city and community level. This article concludes that although there has been no "social avalanche" as requested by Fischer et al. (2012, p. 158), major barriers to implementing sustainable development have and are being removed by concerted action that applies the subsidiarity principle despite the inertia of many national governments and denial of private enterprises to address persistent problems in a rapidly changing world.

\section{Acknowledgement}

Dr. Arthur Dahl, former Deputy Assistant Executive Director of the United Nations Environment Programme (UNEP) has kindly provided feedback on an earlier draft of this article despite his busy schedule during his active retirement. His generosity is acknowledged with sincere thanks. 


\section{References}

Berg, C. (2020). Sustainable action: Overcoming the barriers. Routledge.

Dahl, A. L. (1996). The eco principle: Ecology and economics in symbiosis. Zed Books.

Dahl, A. L. (2018). UNEP and CSD process for sustainable development indicators. In S. Bell and S. Morse (Eds.), Routledge handbook of sustainability indicators (pp. 347363). Routledge. doi.org/10.4324/9781315561103-23

Daly, H. (1973). Toward a steady-state economy. W. H. Freeman.

Dovers, S. R., \& Handmer, J. W. (1993). Contradictions in sustainability. Environmental Conservation, 20(3), 217-222. doi.org/10.1017/s0376892900022992

Dyball, R., \& Newell, B. (2015). Understanding human ecology: A systems approach to sustainability. Routledge.

Elder, M., Bengtsson, M., \& Akenji, L. (2016). An optimistic analysis of the means of implementation for Sustainable Development Goals: Thinking about goals as means. Sustainability, 8(9), 962. doi.org/10.3390/su8090962

Fischer, J., Dyball, R., Fazey, I., Gross, C., Dovers, S., Ehrlich, P. R., ... Borden, R. (2012). Human behavior and sustainability. Frontiers in Ecology and the Environment, 10(3), 153-160. doi.org/10.1890/110079

International Council for Science. (2017). A guide to SDG interactions: From science to implementation. International Council for Science. council.science/wp-content/ uploads/2017/05/SDGs-Guide-to-Interactions.pdf

Kenny, C. (2015). From MDGs to SDGs: Have we lost the plot? [Essay]. Center for Global Development. www.cgdev.org/publication/mdgs-sdgs-have-we-lost-plot

Kolodny, N., \& Brunero, J. (2018). Instrumental rationality. In E. N. Zalta (Ed.), The Stanford encyclopedia of philosophy (Spring 2020 ed.). Stanford University. plato. stanford.edu/archives/spr2020/entries/rationality-instrumental/

Lawrence, R. (2001). Human ecology. In M. Tolba (Ed.), Our fragile world: Challenges and opportunities for sustainable development (Vol. 1; pp. 675-693). EOLSS Publishers.

Lawrence, R. (2005). Human ecology and its applications for sustainability research. In W. Leal Filho (Ed.), Handbook of sustainability research (pp. 121-145). Peter Lang.

Lawrence, R. (2015). Mind the gap: Bridging the divide between knowledge, policy and practice. In H. Barton, S. Thompson, S. Burgess, \& M. Grant (Eds.), The Routledge handbook of planning for health and well-being (pp. 74-84). Routledge. doi.org/10.4324/ 9781315728261

Lawrence, R. (2020). Creating built environments: Bridging knowledge and practice divides. Routledge. doi.org/10.4324/9781351201674 
Lawrence, R., \& Gatzweiler, F. (2017). Wanted: A transdisciplinary knowledge domain for urban health. Journal of Urban Health, 94(4), 592-596. doi.org/10.1007/s11524-017$0182-\mathrm{x}$

Lawrence, R., \& Werna, E. (2009). Labour conditions for construction: Building cities, decent work and the role of local authorities. Wiley-Blackwell.

Lopez-Claros, A., Dahl, A., \& Groff, M. (2020). Global governance and the emergence of global institutions for the 21st century. Cambridge University Press. doi.org/10.1017/ 9781108569293

Meadows, D. H. (1998). Indicators and information systems for sustainable development: A report to the Balaton Group. The Sustainability Institute. donellameadows.org/wp-content/user files/IndicatorsInformation.pdf

Monkelbaan, J. (2019). Governance for the Sustainable Development Goals: Exploring an integrative framework of theories, tools, and competencies. Springer Nature. doi.org/10.1007/ 978-981-13-0475-0

Morton, S., Pencheon, D., \& Squires, N. (2017). Sustainable Development Goals (SDGs), and their implementation: A national global framework for health, development and equity needs a systems approach at every level. British Medical Bulletin, 124(1), 81-90. doi.org/10.1093/bmb/ldx031

Nilsson, M., Griggs, D., \& Visbeck, M. (2016). Map the interactions between Sustainable Development Goals. Nature, 534(7607), 320-322. doi.org/10.1038/534320a

Pintér, L., Almassy, D., Antonio, E., Hatakeyama, S., Niestroy, I., Olsen, S., \& Pulawska, G. (2014). Sustainable Development Goals and indicators for a small planet: Part Imethodology and global framework. Asia-Europe Foundation.

Rittel, H., \& Webber, M. (1973). Dilemmas in a general theory of planning. Policy Sciences, 4, 155-169. doi.org/10.1007/bf01405730

Scharmer, C. O. (2016). Theory U: Leading from the future as it emerges (2nd ed.). BerrettKoehler Publishers.

Scharmer, C. O. (2018). The essentials of Theory U: Core principles and applications. BerrettKoehler Publishers.

United Nations. (1992). Agenda 21: Programme of action for sustainable development. United Nations Conference on Environment and Development, Rio de Janeiro, Brazil, 3-14 June. United Nations. sustainabledevelopment.un.org/content/documents/Agenda21.pdf

United Nations. (2002). Report of the World Summit on Sustainable Development. United Nations. digitallibrary.un.org/record/478154? ln=en

United Nations. (2015). Transforming our world: The 2030 agenda for sustainable development. United Nations. sustainabledevelopment.un.org/post2015/transforming ourworld/publication 
United Nations. (2017). Progress towards the Sustainable Development Goals: Report of the Secretary-General. United Nations. digitallibrary.un.org/record/1288024? ln=en

United Nations. (2019). Global sustainable development report 2019: The future is now-Science for achieving sustainable development. United Nations. doi.org/10.18356/5d04ad97-en

WBGU. (2011). World in transition: A social contract for sustainability. Wissenschaftlicher Beirat der Bundesregierung Globale Umweltveränderungen [German Advisory Council on Global Change] (WGBU). issuu.com/wbgu/docs/wbgu_jg2011_en?e=37591641/ 69400200

World Commission on Environment and Development. (1987). Our common future [The Brundtland Report]. Oxford University Press. 
This text is taken from Human Ecology Review, Volume 26, Number 1, 2020, published by ANU Press, The Australian National University, Canberra, Australia. doi.org/10.22459/HER.26.01.2020.08 